\title{
Anthropometrics revisited
}

By M. D. BASTow, The University Hospital, Queen's Medical Centre, 'Nothing is measured with greater error than the human body'

(BENEKE, 1878)

The effects of malnutrition on the morbidity and mortality of the sick have been recognized since the time of Hippocrates. In 1962 Fletcher proposed the use of techniques, originally developed for assessing body composition from population studies (Brozek, 1956), to study nutritional changes in disease and monitor the effects of dietary therapy. These techniques of anthropometric measurement have been popularized by Blackburn (r977) for assessing fat reserves and somatic protein mass in hospitalized patients.

Unfortunately, it has become evident that the application of these methods to the individual patient can be misleading and inaccurate. Tables of 'normal' reference values give little weight to the widespread variation between individuals and so often comparison is made between the individual and population norms derived from different racial and geographical data or outdated population statistics.

In this paper I propose to re-examine the rationales for the use of measurements of weight, height, skinfold thickness and arm muscle circumference in nutritional assessment, and to indicate some of their limitations.

\section{Body-weight}

Probably the simplest measurements made in the nutritional assessment of an individual are weight and height. Body-weight values are usually related either to the individual's previous weight or, after correction for their stature above or below the average, to 'ideal' values in order to assess their leanness or obesity.

Changes in body-weight can reflect changes in body fat and hence the adequacy of energy intake, but changes in salt and water can easily mask these in an individual, and in malnourished subjects weight may remain constant for several weeks even on a high energy intake (Feurer et al. I980). Despite this, however, changes in body-weight over a long period are probably the best indicator of a change in nutritional state.

The importance of weight loss was shown by the classic study of Studley (1936) who found an increase in mortality among patients undergoing surgery for peptic ulceration who had lost $20 \%$ or more of their body-weight. The significance of lesser degrees of weight loss is unclear (Ryan \& Taft, I 980). In the assessment of an individual's weight loss comparison is made with a value for their 'usual' weight, usually obtained by subject recall. This limits the importance of this type of assessment as values for recalled weight (when available) are subject to considerable error (Morgan et al. 1980 ). 
The ratio of an individual's observed weight to a 'standard' weight is often used as an index of adiposity. Probably the most commonly used standard is that relating to an American population-the Metropolitan Life Insurance Table - where weight is corrected for height. The data for these actuarial standards were obtained from that section of the American population whose lives were proposed for insurance and is therefore subject to self-selection. In these Tables ranges of 'desirable' weights are given for people of a given height and frame; the desirable weights being those associated with the lowest mortality. Unfortunately, no definition is given for the different frame sizes quoted, the frequency distribution of weight values being simply divided into thirds and assigned a label of large, medium or small. As body-frame size has a significant impact on ideal weight a method for determining frame size has been proposed (Grant, I980) based on the ratio of height to wrist circumference, but this has not been widely adopted. Of recent interest is the published data compiled from the American HANES II (1979) study dividing body-weight for age into population percentiles for men and women. The data for this study was not analysed for frame size or height and is not intended to indicate an 'ideal' value for weight. However, in conjunction with norms for other anthropometric measurements derived from the same population, this type of information allows evaluation of an individual using their predicted percentile as a reference. Data on a similar scale for a UK population is awaited.

A further type of indirect measure of obesity or leanness relating weight to height is the so-called 'power' index where weight is expressed as a power function of height. Many different indices have been proposed including the simple ratio of weight/height, Quetelets index Wt/ $\mathrm{Ht}^{2}$ and the ponderal index $\mathrm{Ht} / \mathrm{Wt}^{3}$ (Keys et al. 1972). None of these indices is consistently independent of height in all populations, but $\mathrm{Wt} / \mathrm{Ht}^{2}$ tends to be least height biased (Khosla \& Lowe, 1967; Florey, 1970; Goldbout \& Medalie, 1974; Womersley \& Durnin, 1977). Recently $\mathrm{Wt} / \mathrm{Ht}^{2}$ has been proposed as perhaps the best single anthropometric indicator of total body fat in adults (Roche et al. 198I). A further refinement of this index (Benn, 197 I), where height is raised to a power value ' $P$ ' derived from observed weight/height data for a given population: $\mathrm{Wt} / \mathrm{Ht}^{P}$, has been proposed (Lee et al. I98r).

The cautionary tale of how professional football players were found to be on average $25 \%$ overweight (and hence classified as 'obese') using American Army acceptance standards should not be forgotten (Welham \& Behnke, I942) when interpreting weight/height indices. Values for measurement of weight related to height compared to standard values cannot on their own differentiate between differences in weight due to fat, muscle or bone.

Use of the aforementioned height-dependent indices runs into further problems when considering elderly subjects. Two problems are manifest, firstly the paucity of representative information for this section of the population and secondly the decrease in height, both apparent and real, that occurs with ageing. The apparent decline can be attributed partly to the general increase in height and body size that has occurred over the past few generations (secular trend). People are tending to 
become taller and the magnitude of the increase seems to be at a rate of about I cm/decade (Bakwin \& McLaughlin, I964). However, of greater importance are the changes that occur in the individual as part of the normal ageing process, predominantly shortening of the spinal column without any significant reduction in the size of the long bones (Trotter \& Gleser, I951 ; Miall et al. I967; Rossman, 1979). Other contributory factors include kyphosis, scoliosis and thinning of all weight-bearing cartilages (Stoudt, I98I). Curvature of the spine often makes it extremely difficult for some elderly people to stand up straight enough for an accurate measurement of height to be made, adding further to the difficulties of using height measurement in assessing the elderly. It may be that measurement of long-bone lengths in these people might enable a prediction of their height to be made (Trotter \& Gleser, I95 I ; Zorab et al. I963) should weight/height indices be required, but at present the limited information available for the elderly coupled with the changes in stature due to ageing make interpretation of these indices difficult.

The comparison of weight for height with so called 'ideal' body-weight values in nutritional assessment is at present unsatisfactory-the standard tables at present available are far from ideal in many aspects. Comparison with usual body-weight is probably better and avoids the need for tables of standard values. This makes assumptions, however, about the accuracy of recall which may be equally invalid, particularly in the elderly. The use of weight for age percentiles and power type indices needs further evaluation.

\section{Subcutaneous fat thickness}

Because of the limitations of using body-weight, even when corrected for height, to assess body fat, various other methods have been developed including body densitometry and estimation of body water and potassium. However, these methods are not usually applicable in the clinical situation. Although little direct information is available on the proportion of total body fat that is located subcutaneously (Alexander, 1964; Moore et al. 1968) it has been assumed that measurements of subcutaneous fat would give an index of total body fat. Despite the considerable inherent errors in the methods for determining total body fat (see, for example, Womersley \& Durnin, I 977) comparisons have been made with the various techniques of measuring subcutaneous fat. Correlations vary depending on the site and method employed, but the values obtained range from $r 0.4-0.9$, with an average of about 0.8 (Brozek \& Keys, 1951; Brozek \& Mori, 1958; Young et al. 1963; Sloan, 1967; Durnin \& Womersley, 1974; Womersley \& Durnin, I977).

The distribution of subcutaneous fat varies from individual to individual and also probably changes with ageing (Durnin \& Womersley, 1974) but alterations with dietary changes appear to occur proportionately throughout the body (Brozek et al. 1957), hence it is assumed that changes in subcutaneous fat reflect changes in total body fat.

Three principle methods are used to measure subcutaneous fat thickness in humans: skinfold calipers, soft tissue radiography and ultrasound. Of these the 
most popular is the use of skinfold calipers. Additionally, subcutaneous fat thickness has been measured by needle puncture (Bullen $e t$ al. 1965) and electrical conductivity (Booth et al. 1966) but these techniques are not generally applicable for clinical use.

In considering the methods used for measuring subcutaneous fat thickness questions relating to the reproducibility, validity and availability of appropriate reference information for the various techniques need to be examined in addition to questions of ease of use and expense.

Repetitive measurements by one trained observer using skin calipers to measure the thickness of a fold of skin plus subcutaneous fat have been shown to be relatively reproducible, the standard deviation of the difference between duplicate measurements being about $4-8 \%$ (Edwards et al. 1955). However, measurements made by different observers on different days may have a coefficient of variation of up to $22 \%$ (Hull et al. 1980). In addition, the larger the caliper jaw opening the less the absolute accuracy and reproducibility of the readings. Hence the importance of using a single observer when taking serial measurements to assess changes in subcutaneous fat.

The shadow of skin plus subcutaneous tissue can be easily distinguished from that of the underlying muscle on a suitably exposed X-ray film, and using standardized conditions this fact is made use of for radiographic measurement of subcutaneous fat. The relative errors in measuring subcutaneous fat thickness by this method are quoted as $3-5 \%$ (Tanner, 1965 ).

Ultrasonic techniques for measuring fat thickness rely on the reflection of sound waves from the various tissue-plane boundaries. This technique is claimed to be more reliable than caliper measurements (Whittingham, 1962; Haymes \& Lundergran, 1976) but insufficient data are, as yet, available.

Thus it seems that the inherent errors in skinfold thickness measurements are higher than for radiographic or ultrasound measurements of subcutaneous fat thickness. In trying to validate the various methods two different approaches have been used. Firstly comparisons have been made between estimates of total body fat and the various methods for measuring subcutaneous fat (Brozek \& Mori, 1958; Sloan, 1967; Durnin \& Womersley, 1974; Steen et al. 1977; Womersley \& Durnin, 1977), and secondly correlations between the various techniques of measuring subcutaneous fat at different sites have been examined (Himes, 1980). These results suggest that skinfold thickness measurements with calipers correlate with total body fat slightly better than radiographic or ultrasound techniques, but skinfold measurements do not estimate subcutaneous fat thickness as well as the other techniques. The correlation between skinfold measurements and subcutaneous fat thickness varies between 0.6 and 0.9 (Himes, 1980 ) depending on the site and method employed. If 0.85 is taken as a representative value then a skinfold can only account for about $72 \%$ of the variance in actual fat thickness (Himes et al. 1979). Some of the difference between skinfold thickness measurements and other estimates of subcutaneous fat can be accounted for by skinfold compression, variation of which will occur due to variation in caliper 
pressure (Edwards et al. 1955) and skinfold compressibility. Skinfolds in females tend to be more compressible than those of males, and compressibility tends to decrease with age (Brozek \& Kinzey, 1960). Whether making allowances for changes in skin compressibility would significantly affect estimates of subcutaneous and total body fat is, however, unknown (Durnin \& Womersley, 1974; Himes et al. 1979).

When the various methods are assessed in terms of expense, ease of use and the availability of suitable reference data, then skinfold calipers emerge the winner. The standard calipers (Harpenden and Lange) are relatively cheap, portable and can be used in many different situations. Plastic calipers have recently been made available from several pharmaceutical companies but their accuracy and reproducibility do not compare with the standard calipers (Burgert \& Anderson, 1979). With all types of caliper, practice is needed before adequate reproducibility of results can be obtained.

It perhaps goes without saying that skinfolds can be accurately measured only at sites where a proper fold can be raised, and with very obese individuals caliper measurements are limited by the ability to pick up a proper skinfold and the upward limitation of the jaw opening. The most commonly measured skinfolds are the triceps and subscapular, usually on the left side, but this custom is not universally adhered to and standardization of the side to be measured is required. Roche (1979), after reviewing the published literature, has suggested that measurements should be made at a variety of sites including the anterior chest wall, triceps, subscapular, midaxillary and paraumbilical sites; unfortunately most of the reference data presently available relates to triceps and subscapular measurements only.

Radiographic and ultrasonic techniques have disadvantages when consideration is made of ease of use and cost. Considerable expertise and capital outlay is required for either technique. Ultrasonic instruments for assessing the leanness of livestock are being evaluated for use in human work, but at present little reference information is published for ultrasonic or radiographic techniques.

Thus over-all the most practical method of assessing subcutaneous fat thickness is the use of skinfold calipers. Estimations of total body fat can be made from regression equations (Durnin \& Womersley, 1974) for skinfold thickness or skinfold percentiles can be used in conjunction with percentiles for weight and weight/height indices and compared with percentiles from nationally representative samples (Frisanchio, $198 \mathrm{I}$ ). Estimation of 'degrees' of malnutrition is not recommended.

\section{Arm muscle circumference and area}

In 1974 Bistrian et al. proposed that measurements of mid-arm muscle circumference could be used as a clinical indicator of nutritional state, and more recently Blackburn (1977) has suggested that this is one of the best available measurements of protein-energy malnutrition. The proposition is that the measured value of arm circumference reflects the underlying muscle bulk, that this 
can be taken as a general indicator of skeletal muscle protein mass, and that changes in serial measurements reflect changes in somatic protein mass. Additionally, calculation of a value for the area of the upper arm muscle has been suggested from the arm circumference and the triceps skinfold thickness (Gurney \& Jelliffe, r973) and reference to standard tables for arm muscle circumference and arm muscle area have then been used to estimate the 'degree' of malnutrition. These measurements assume that both the arm and arm muscle are circular in cross section and that the bone area can be neglected. Clearly these assumptions produce variable degrees of error in the measurements. Additionally, as the arm is in fact fusiform in shape, great care must be taken to ensure that the circumference and skinfold thickness measurements are made at the mid-point as even a slight displacement may significantly affect serial measurements.

The coefficient of variation of measurements of upper arm circumference by different observers can be as much as $5 \%$ (Hull et al. I980) and the combined variance of skinfold thickness and arm muscle circumference can produce an error of up to $33 \%$ in arm muscle area determinations between different observers (Mullen et al. 1979). This error can probably only be reduced to about $10 \%$ even with a single observer, making serial comparisons of arm muscle area very insensitive to changes in muscle mass.

Comparison between anthropometric measurements and body nitrogen estimation by neutron activation analysis (Collins et al. 1979) suggests that measurements of arm muscle circumference and area are not suitable for detecting changes in body nitrogen in individual patients over short periods of time (e.g. 2 weeks).

Unfortunately at present there appears to be no reliable method by which body skeletal muscle mass can be easily assessed. The anthropometric measurements available, because of their inherent limitations, can only be regarded as of very limited value in supporting the clinical impression.

\section{Summary}

This paper has discussed some of the anthropometric techniques currently used for assessing nutritional state. Most of the measurements are easy to perform and a large amount of reference information is available, and yet an accurate and clinically useful method for nutritional assessment (especially for the elderly) has yet to be achieved.

At present the best compromise would appear to be the use of measurements of weight, height and skinfold thickness at several sites to estimate the individual's body fat (and hence estimate 'energy reserves') from regression equations, or in conjunction with a prediction of their usual percentile, from national surveys, to try and gauge losses or gains in fat. 'The estimation of 'degrees' of malnutrition is not recommended. 


\section{REFERENCES}

Alexander, M. K. (1964). Clin. Sci. 26, I93.

Bakwin, H. \& McLaughlin, S. K. (1964). Lancet i, I I95.

Benn, R. T. (197I). Br. F. prev. soc. Med. $25,42$.

Bistrian, B. R. G., Blackburn, G. L., Hallowell, E. \& Heddle, R. (1974). F. Am. med. Ass. 230, $85^{8}$. Blackburn, G. L. (I977). In Nutritional Support of Medical Practice. [H. A. Schneider, C. E. Anderson and D. B. Coursin, editors]. New York: Harper and Row.

Blackburn, G. L., Bistrian, B. R. G., Maini, B. S., Schlamm, H. T. \& Smith, M. F. (I977). F. parent. ent. Nutr. I, II.

Booth, R. A. D., Goddard, B. A. \& Paton, A. (1966). Br. F. Nutr. 20, 719.

Brozek, J. (1956). Human Biol. 28, I24.

Brozek, J., Grande, F. \& Anderson, J. T. (1963). Ann N.Y. Acad. Sci. r10, I 13.

Brozek, J., Grande, F., Taylor, H. L., Anderson, J. T., Buskirk, E. R. \& Keys, A. (1957). F. Appl. physiol. 10, 412 .

Brozek, J. \& Keys, A. (195I). Br. F. Nutr. 5, I44.

Brozek, J. \& Kinzey, W. (1960). F. Gerontol. 15, 45.

Brozek, J. \& Mori, H. (1958). Human Biol. 30, 322.

Bullen, B. A., Quaade, F., Olesen, E. \& Lund, S. A. (1965). Human Biol. 37, 375.

Burgert, L. \& Anderson, C. F. (1979). Am. F. clin. Nutr. 32, I531.

Collins, J. P., McCarthy, I. D. \& Hill, G. L. (1979). Am. F. clin. Nutr. 32, 1527.

Durnin, J. V. G. A. \& Womersley, S. (1974). Br. F. Nutr. 32, 77.

Edwards, D. A. W., Hammond, W. H., Healey, M. J. R., Tanner, J. M. \& Whitehouse, R. H. (1955). Br. Y. Nutr. 9, I33.

Feurer, I., Crosby, L. \& Perlschuk, M. (1980). F. parent. ent. Nutr. 4, $5^{84}$.

Fletcher, R. F. (1962). Clin. Sci. 22, 333.

Florey, C. D. V. (1970). F. Chron. Dis. 23, 93.

Frisanchio, A. R. (I98I). Am. F. clin. Nutr. 34, 2540.

Goldbout, U. \& Medalie, J. H. (1974). Br. F. prev. soc. Med. 28 , I 16.

Grant, J. P. (1980). Handbook of Total Parenteral Nutrition, p. 15. Philadelphia: W. B. Saunders. Co.

Gurney, J. M. \& Jelliffe, D. N. (1973). Am. F. clin. Nutr. 26, 912.

HANES II. (1979). Vital Health Statistics. US 1971-74 DHEW publication no. (PJS) 79-1656, series no 212 . Washington DC: Government Printing Offices.

Haymes, E. M. \& Lundergran, H. M. (1976). Ann. Hum. Biol. 3, 245.

Himes, J. H. (t980). Social and Biological Predictors of Nutritional Status, Physical Growth and Neurological Development, pp. 9-32 [L. S. Greene and F. E. Johnstone, editors]. New York: Academic Press.

Himes, J. H., Roche, A. F. \& Siervogal, R. M. (I979). Am f. clin. Nutr. 32, I 743.

Hull, J. C., O'Quigley, J., Giles, G. R., Appleton, N. \& Stocks, H. (I980). Am. F. clin. Nutr. 33, 1846 .

Keys, A., Fidanza, F. \& Karvouen, M. J. (1972). F. Chron. Dis. 25, 329.

Khosla, T. \& Lowe, C. R. (1967). Br. F. prev. soc. Med. 21 , 22.

Lee, J., Kolonel, L. N. \& Hinds, M. W. (1981). Am. f. clin. Nutr. 34, 252 I.

Metropolitan Life Insurance Company (1959). Statist. Bull. 40, r.

Miall, W. E., Ashcroft, M. T. \& Lovell, H. G. (1967). Human Biol. 39, 445.

Moore, F. D., Lister, J. \& Boyden, C. M. (I968). Human Biol. 40, I35.

Morgan, D. B., Hill, G. L. \& Burkinshaw L. (I980). Am. F. clin. Nutr. 433, 2 Ior.

Mullen, J. L., Buzby, G. P., Waldman, M. T., Gertuer, M. H., Hobbs, C. L. \& Rosato, E. F. (I979). Surg. Forum 30, 80.

Roche, A. F. (1979). Stud. phys. anthrop. 5, 53.

Roche, A. F., Siervogal, R. M., Chumlea, W. C. \& Webb, P. (I98I). Am. F. clin. Nutr. 34, 283 I.

Rossman, J. (1979). In Clinical Geriatrics, 2nd ed., pp. 3-22 [J. Rossman, editor]. Philadelphia: J. B. Lippincott Co.

Ryan, J. A. \& Taft, D. (1980). Surg. Forum 31, 96.

Sloan, A. W., (1967). F. Appl.physiol. 23, 3 I r. 
Steen, B., Bruce, A., Isaksson, B., Lewin, T. \& Svanborg, A. (1977). Acta Med. Scand. Suppl. 6II, 87 .

Stoudt, H. W. (1981). Human Factors 23, 29.

Studley, H. O. (1936). F. Am. med. Ass. 106, $45^{8}$.

Tanner, J. M. (1965). In Human Body Composition, pp. $211-36$ [J. Brozek, editor]. Oxford: Pergamon Press.

Trotter, M. \& Gleser, G. (1951). Am. F. phys. anthrop. 9, 3 I 1.

Welham, W. C. \& Behnke, A. R. (1942). F. Am. med. Ass. 1 18, 498.

Whittingham, P. D. V. (1962). Aerospace med. 33, I2 I.

Womersley, S. \& Durnin, J. V. G. A. (1977). Br. F. Nutr. 38, 27 r.

Young, C. M., Tensuan, R. S., Sault, F. \& Holmes, F. (1963). Y. Am. Dietetic Ass. 92, 409.

Zorab, P. A., Prime, F. J. \& Harrison, A. (1963). Lancet i, 195 . 